\title{
Chemical and Biological National Security Program (CBNP) Annual Report FY2002 Overview Local Integration of NARAC with Cities (LINC)
}

D.L. Ermak, J.S. Nasstrom, J.E. Tull, R.L. Baskett, B. Pobanz, and R. Mosley-Rovi

November 18, 2002

Lawrence Livermore National Laboratory

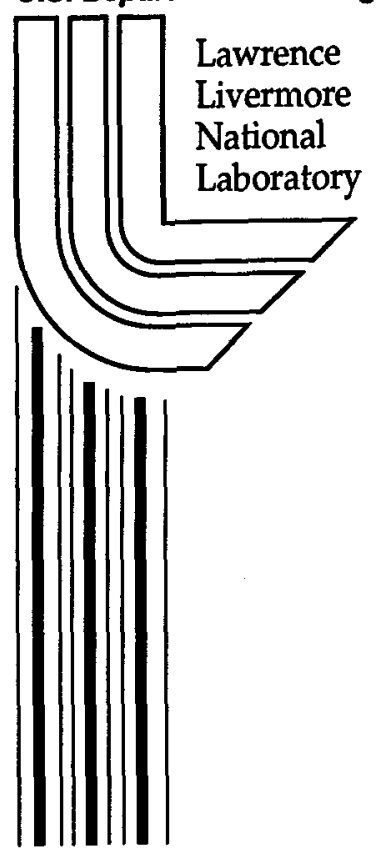




\section{DISCLAIMER}

This document was prepared as an account of work sponsored by an agency of the United States Government. Neither the United States Government nor the University of California nor any of their employees, makes any warranty, express or implied, or assumes any legal liability or responsibility for the accuracy, completeness, or usefulness of any information, apparatus, product, or process disclosed, or represents that its use would not infringe privately owned rights. Reference herein to any specific commercial product, process, or service by trade name, trademark, manufacturer, or otherwise, does not necessarily constitute or imply its endorsement, recommendation, or favoring by the United States Government or the University of California. The views and opinions of authors expressed herein do not necessarily state or reflect those of the United States Government or the University of California, and shall not be used for advertising or product endorsement purposes.

This work was performed under the auspices of the U. S. Department of Energy by the University of California, Lawrence Livermore National Laboratory under Contract No. W-7405-Eng-48.

This report has been reproduced directly from the best available copy.

Available electronically at http://www.doc.gov/bridge

Available for a processing fee to U.S. Department of Energy

And its contractors in paper from

U.S. Department of Energy

Office of Scientific and Technical Information

P.O. Box 62

Oak Ridge, TN 37831-0062

Telephone: (865) 576-8401

Facsimile: (865) 576-5728

E-mail: reports@adonis.osti.gov

Available for the sale to the public from

U.S. Department of Commerce

National Technical Information Service

5285 Port Royal Road

Springfield, VA 22161

Telephone: (800) 553-6847

Facsimile: (703) 605-6900

E-mail: orders@ntis.fedworld.gov

Online ordering: http://www.ntis.gov/ordering.htm

\section{OR}

Lawrence Livermore National Laboratory

Technical Information Department's Digital Library

http://www.llnl.gov/tid/Library.html 


\section{Chemical and Biological National Security Program (CBNP) Annual Report FY 2002}

\section{OVERVIEW}

\section{Local Integration of NARAC With Cities (LINC)}

\section{Domestic Demonstration and Application Program (DDAP)}

Donald L. Ermak, Lawrence Livermore National Laboratory (925) 423-0146, email: ermak1@1lnl.gov

Co-Investigators: John S. Nasstrom, Joseph E. Tull,

Ronald L. Baskett and Brenda Pobanz (Lawrence Livermore National Laboratory) and Ronda Mosley-Rovi (Public Technology, Inc.)

\section{Objectives}

The objective of the Local Integration of NARAC With Cities (LINC) project is to demonstrate the capability for providing local government agencies with advanced, CBNP-developed operational atmospheric plume prediction capabilities that can be seamlessly integrated with appropriate federal agency support for homeland security. LINC s approach is to integrate Lawrence Livermore National Laboratory s (LLNL) National Atmospheric Release Advisory Center (NARAC) tools and services with local emergency management and response centers.

In the event of an airborne chemical or biological agent release in an urban area, large portions of the city and even the surrounding suburbs may be affected by the airborne plume, depending on the type of agent, size of release, dissemination mechanism and ambient meteorological conditions. The goal of LINC is to provide real-time predictions that would be used by emergency managers and responders (fire, police, hazmat, etc.) to map the extent and effects of hazardous airborne material. Prompt predictions are provided to guide first responders in determining protective actions to be taken (use of personal protective equipment, evacuation, sheltering in place, etc.), safe locations for incident command posts, and critical facilities that may be at risk (hospitals, schools, etc.). LINC also provides response teams from multiple jurisdictions (local, state, and federal) with tools to effectively share information regarding the areas and populations at risk.

The ultimate goal of LINC is a seamless and coordinated nationwide system that integrates NARAC prediction and situation awareness resources with the appropriate local, state and federal agencies for homeland security applications ranging from planning to emergency response to consequence assessment and attribution.

\section{Highlights}

During this first year of the LINC program, selection criteria were developed and applied to select the first LINC pilot city, the City of Seattle, Washington. LLNL met with local city departments and groups to obtain full acceptance and support, up to and including the Seattle Mayor s Office. A very effective partnership was established with the Seattle Fire Department, Hazmat Unit, Emergency Operations Center, Geographical Information System (GIS) group, and Information Technology Department. This and future partnerships with local government 
agencies are being facilitated by Public Technology, Inc. (PTI), the nonprofit technology organization of the National League of Cities and the National Association of Counties.

A significant effort to customize NARAC software tools and databases for Seattle was completed by LLNL, and now allows Seattle users of the NARAC iClient (internet client) software to request NARAC plume predictions and display them over detailed city geographical information layers, including fire stations, city streets, and landmarks (see Figure 1 for an example). LLNL established automated access to local meteorological observation networks, as well as local terrain and land use data for the Seattle area, for use in model predictions.

$<$ Figure 1: Insert file LINCOverview-Fig1.jpg. Crop as shown below. Figure caption is below $>$

Figure 1 Caption: Example NARAC plume prediction displayed using iClient software tools and showing hazardous air concentration levels on maps with key geographical features, such as roads, schools, and hospitals.

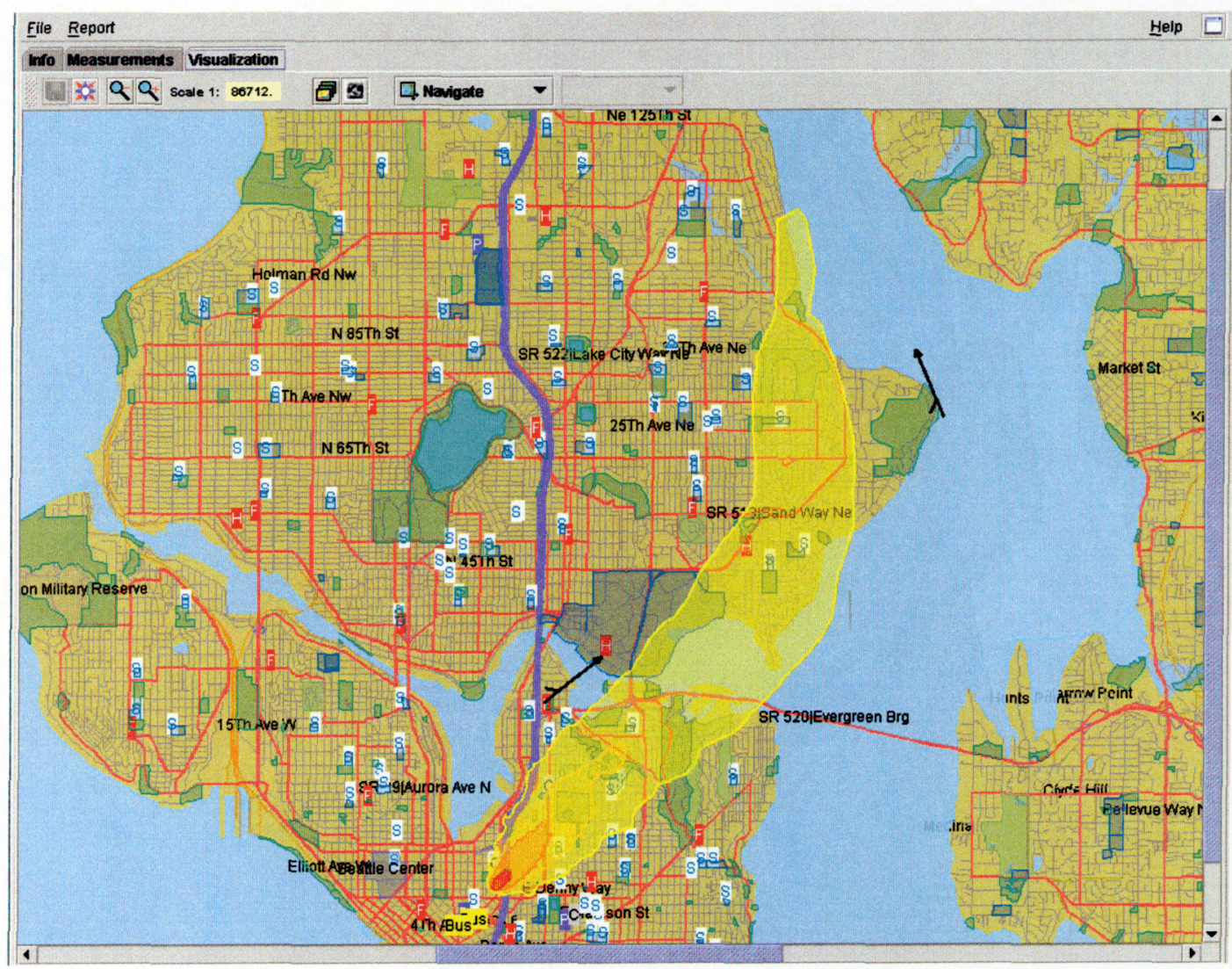

Installation, configuration, and testing of the iClient software, was successfully completed in the 
Seattle Fire Department. Network connections were established between the Seattle city network and NARAC to allow secure transmission of iClient plume-prediction requests to the NARAC facility at LLNL, and to receive advanced 3-D plume model predictions.

As part of an ongoing training program, training materials were developed, hands-on training was conducted in Seattle, and a two-day hands-on training course for Seattle Fire Department users was held at LLNL (see Figure 2). One HazMat team member per fire department shift was trained. The response from attendees was very positive. Course evaluations and comments indicated that NARAC was providing an excellent set of tools and services that would be valuable to local agencies.

$<$ Insert files LINCOverview-Fig2-Frame1.jpg AND LINCOverview-Fig2Frame2.jpg . Crop and overlap as show below. Figure caption below>

Figure 2 Caption: A two-day training course was held for Seattle LINC users, as well as for representatives from potential future pilot cities.

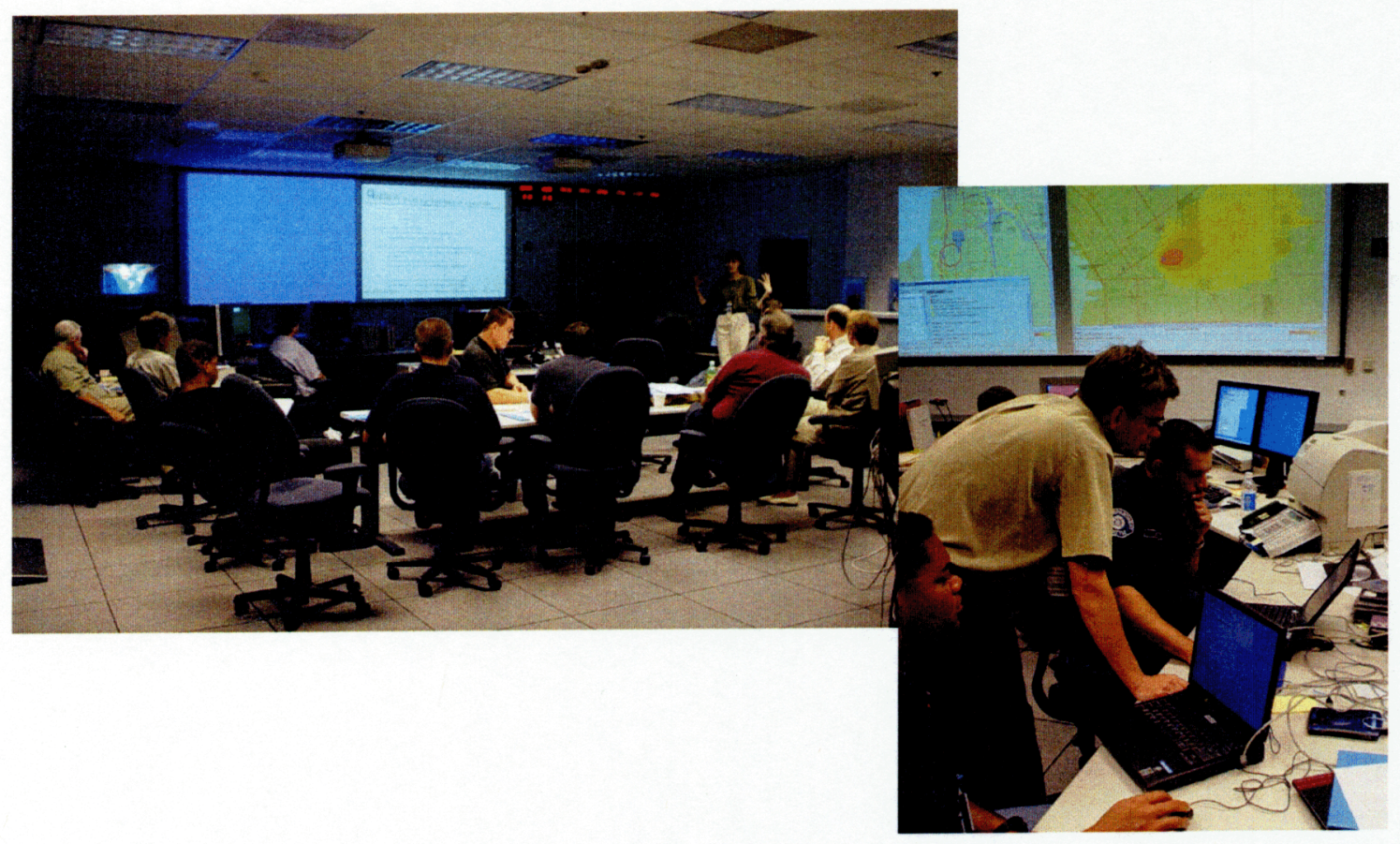


During the period from June through September, the NARAC iClient software has been operational in the Seattle Fire Department, and has been utilized for numerous tests and demonstrations. On July 25, 2002, a briefing and demonstration was given to Chief A.D. Vickery, Seattle Fire Department, Chief Bryant, Seattle Police Department and Dr. Joseph Allbaugh, FEMA Director. Drills involving NARAC staff and Seattle Fire Department staff are being designed and will be conducted on a monthly basis.

Outreach to a broad user base is essential to the success of the LINC project. Presentations and demonstrations were made at the Public Technology, Inc. (PTI) Annual Conference, which was attended by representatives from over 200 local governments. A LINC-PTI User Requirements Committee, which includes representatives from 4 cities, was formed to review the NARACSeattle integration and to provide NARAC/CBNP/PTI with user requirements from non-pilot cities. This review highly praised the progress and potential of the LINC program.

\section{Impact}

This demonstration project provides a transition of advanced modeling and prediction tools for CB agent transport and fate which have been developed with CBNP funding by LLNL and other federal laboratories to multiple levels of government. LINC provides local municipality users with a unique capability consisting of hazardous material atmospheric modeling tools for CB agent dispersion in urban areas, coupled with customized support for these tools from highly trained scientific and technical staff. These tools and services will be easy to use and readily accessible on a variety of commonly available computer hardware platforms, i.e., desktop and laptop, with Internet or other communication links. This approach will provide local responders and emergency managers with not only the tools they need, but also the resources to make the most effective use of them. These tools and services include the following:

- Advanced urban plume modeling using access to real-time local meteorological observations and forecasts

- Combined displays of plume model predictions and geographical information for planning and decision support

- Predictions of hazard zones for decisions regarding evacuation, sheltering, personal protective equipment, traffic control, as well as safe zones for incident command posts and relocation of people

- Predictions of expected health effects, as well as the size of affected population, for decisions regarding impacts on public safety, health and health services

- $24 \times 7$ assistance from NARAC scientific and technical staff before, during and after an incident

- Web-based tools to easily coordinate these plume prediction and situation awareness products with other local, state, and federal agencies

Other applications of the NARAC system include vulnerability analyses, detector siting, preevent planning, forensics, decontamination/post-event analysis, as well as real-time emergency response.

\section{Next Steps}

Next year, the LINC program plans to expand LINC-NARAC support to Seattle by exploring 
new and more effective ways of communicating NARAC results to first responders using wireless technology, as well as to neighboring cities and state agencies using Web technology. Additional iClient installations are planned for other Seattle city departments. A LINC goal is to be fully integrated and operational in Seattle by the end of calendar year 2002.

Because cities vary significantly in geographic size, population, management, organization, and emergency response and consequence management resources/needs, the LINC program plans to integrate and demonstrate the LINC-NARAC technology within a variety of metropolitan areas of different geographic, demographic and organizational characteristics so that it can be determined how this technology can easily be applied to many cities.

The LINC program plans to fully integrate with the emergency planning and response functions of agencies at each level of government, as well as with the tools that are routinely used by these agencies. To accomplish this, LINC plans to integrate NARAC tools with existing civilian emergency response tools and services provided by other agencies, including the NOAA/EPA CAMEO/ALOHA software that is widely used by many first responder organizations throughout the U.S. and the world (including the fire department in the first LINC pilot city, Seattle) for hazardous material emergency response. A Web-based information distribution system will facilitate rapid distribution of plume predictions and related information to neighboring cities and towns, as well as simultaneous coordination with state emergency management centers and appropriate federal agencies. The LINC program will also explore integration with the Federal Emergency Management Agency (FEMA), the Defense Threat Reduction Agency (DTRA) CATS system, National Guard Civil Support Teams, and DOE s national Emergency Response assets (which already include NARAC for radiological/nuclear incidents).

Upon completion of this three year demonstration project, it is anticipated that LINC capabilities will transition to a full operational status with funding provided by either a consortium of federal agencies (i.e., DHS, FEMA, DoD, DOJ, HHS, EPA, DOT) or possibly federal and city/local government co-funding. The LINC program will develop technical and financial plans for extending the LINC multi-city demonstration project to a system that can be efficiently and economically extended to cities throughout the country.

Acknowledgement. This work was performed under the auspices of the U.S. Department of Energy by the University of California, Lawrence Livermore National Laboratory under contract No. W-7405-Eng-48. 